\title{
Sigilo e Acesso: entendimentos e procedimentos para a adequada disponibilização de informações e dados governamentais abertos
}

\author{
Confidentiality and Access: understandings and procedures for the \\ adequate availability of government information and open data
}

\section{Sigilo y Acceso: entendimientos y procedimientos para la adecuada disponibilidad de informaciones y datos gubernamentales abiertos}

\author{
Francisco José Tavares do Nascimento | francisco.tavares@fiocruz.br \\ Fundação Oswaldo Cruz. Rio de Janeiro, Brasil. \\ Érica de Castro Loureiro | erica.loureiro@fiocruz.br \\ Fundação Oswaldo Cruz. Rio de Janeiro, Brasil.
}

Vanessa de Arruda Jorge | vanessa.arruda@incqs.fiocruz.br

Fundação Oswaldo Cruz. Rio de Janeiro, Brasil.

\section{Resumo}

O presente trabalho relata parte da trajetória da Fiocruz no amadurecimento acerca de questões que perpassam a transparência e o acesso a informações e dados governamentais, a partir da adequada delimitação e criação de procedimentos para lidar com o restrito universo de informações sigilosas nas instituições públicas. O entendimento do acesso à informação como regra e o sigilo como exceção, conforme preconizado pela Lei de Acesso à Informação, não isenta as instituições de pensarem de maneira criteriosa sobre as informações que devem ser protegidas, sob pena de colocar direitos e interesses estratégicos nacionais em risco devido à indiscriminada difusão de informações sigilosas. Este trabalho relata os entendimentos estabelecidos no âmbito da Comissão Permanente de Acesso a Informações da Fiocruz, trabalho que culminou no "Procedimento para Tratamento e Classificação de Informações Sigilosas na Fiocruz", instrumento que orienta os profissionais da instituição na adequada identificação e tratamento das informações sigilosas, atividade que promove a transparência e disseminação de dados e informações ostensivas.

Palavras-chave: Informação Sigilosa; Dados Abertos; Acesso à Informação; Transparência. 


\begin{abstract}
This paper presents part of the understanding process held in Fiocruz concerning questions about transparency, access to information and government data, through the proper delimitation and creation of procedures to deal with the restricted universe of sensitive information in public institutions. The understanding of access to information as a rule, and the secrecy as an exception, principle prescribed in the Brazilian Access to Information Law, does not exempt public institutions from thinking in a careful way about the information that should be protected, at the risk of jeopardizing national strategic rights and interests due to the indiscriminate diffusion of sensitive information. This paper presents the understanding established in the activities of the Permanent Commission for Access to Information of Fiocruz, which culminated in the "Procedimento para Tratamento e Classificação de Informações Sigilosas na Fiocruz ", an instrument for the guidance of professionals of the institution to perform the proper identification and treatment of sensitive information, an activity that promotes transparency and dissemination of data and ostensive information.
\end{abstract}

Keywords: Sensitive information; Open data; Access to information; Transparency.

\title{
Resumen
}

Este trabajo presenta parte del proceso de comprensión en Fiocruz de cuestiones acerca de transparencia, acceso a las informaciones y datos gubernamentales, por medio de la adecuada delimitación y creación de procedimientos para administrar el restricto universo de informaciones reservadas en las instituciones públicas. La comprensión del acceso a la información como regla y el secreto como excepción, como principio prescrito en la Ley de Acceso a La Información brasileña, no desobliga las instituciones públicas a garantizar la protección de las informaciones reservadas, para no poner en riesgo derechos e intereses estratégicos nacionales delante una indiscriminada difusión de informaciones reservadas. Este trabajo presenta la comprensión establecida en las actividades de la Comisión Permanente de Acceso a las Informaciones de Fiocruz que produjo el "Procedimento para Tratamento e Classificação de Informações Sigilosas na Fiocruz", instrumento para orientación de profesionales de la institución realizar la adecuada identificación y tratamiento de informaciones reservadas. Esa actividad promueve la transparencia y difusión de datos e informaciones públicas.

Palabras claves : Información Reservada; Datos Abiertos; Acceso a la Información; Transparencia.

\section{Introdução}

Quais os vínculos entre um trabalho que preza pelo estabelecimento de procedimentos para tratar informações sensíveis e sigilosas institucionais e o trabalho voltado a disponibilização de informações e dados abertos governamentais? O marco normativo acerca da transparência estatal e abertura dos dados governamentais ${ }^{1,2}$ oferece elementos para enfrentarmos essa questão ao definir o objeto do direito de acesso à informação e da abertura de dados como aqueles sobre os quais não recaia nenhuma espécie de sigilo. O presente trabalho pretende relatar parte da trajetória da Fiocruz no amadurecimento a respeito dessa e outras questões que perpassam a transparência e o acesso a informações e dados governamentais, a partir da experiência de sua Comissão Permanente de Acesso a Informações (CPAI/Fiocruz) $)^{3,4}$.

Esta instância, criada nos moldes da Comissão Permanente de Avaliação de Documentos Sigilosos sugerida pelo decreto 7.424/2012 ${ }^{5}$, que regulamenta a lei 12.527/2011 (Lei de Acesso à Informação - LAI), estabeleceu importantes entendimentos para orientar os profissionais da instituição no momento de desenvolver trabalhos voltados à transparência de informação e disseminação de dados abertos. O primeiro entendimento é o de que o universo das informações sigilosas e sensíveis governamentais é bastante restrito, e que, portanto, conforme preconiza a LAI, o sigilo deve ser exceção entre as informações públicas, sendo a regra o acesso. 
Entretanto, tão grave quanto negar indevidamente acesso a informações e dados públicos é o indiscriminado acesso a informações e dados que possam causar danos à instituição que os gerencia, aos seus públicos ou aos interesses estratégicos nacionais ${ }^{6}$. A LAI enquanto norma reguladora de direito fundamental, está direcionada ao público em geral, ou seja, tem caráter universal e vincula a Administração Pública em sua amplitude no que se refere à imposição de deveres ${ }^{7}$.

Nesse sentido, proteger determinados dados pode estar relacionado ao propósito da promoção de uma sociedade mais justa e segura ${ }^{8}$. Por exemplo, ao se tratar de certas análises laboratoriais, atividades que podem fazer parte de um processo de tomada de decisão para uma ação em saúde pública, será preciso que durante seu período de realização as informações e resultados parciais estejam protegidos, de maneira que tais análises sejam devidamente finalizadas. De modo contrário, a disseminação de informações sem quaisquer critérios de restrição, ao menos temporários, como no caso de documentos preparatórios para tomada de decisão, poderia acarretar em interpretações parciais ou errôneas, com potencial de causar julgamentos equivocados e até mesmo pânico na população. Evidencia-se no exemplo a necessidade do estabelecimento de critérios claros para definir o restrito, porém necessário, universo de informações sensíveis e sigilosas ${ }^{9}$, liberando, consequentemente, as demais para acesso.

\section{Definição do objeto de trabalho da CPAI/Fiocruz}

Com esse cuidado e entendimento, o grupo da CPAI/Fiocruz se dedicou a pensar formas de identificar e trabalhar com informações consideradas sensíveis e potencialmente sigilosas, seja nos termos da Lei de Acesso à Informação (informações pessoais, classificáveis e preparatórias para tomada de decisão), seja de outras legislações específicas. Por informação sensível entendemos aquelas informações cuja divulgação possam pôr em risco determinado direito e que ainda não tenha sido submetida à análise para se verificar a ponderação de razoabilidade e proporcionalidade com o direito de acesso à informação. Na medida em que tal informação é submetida a essa análise e lhe é atribuída a restrição de acesso, tal informação torna-se uma informação sigilosa.

Se a atribuição de sigilo visa garantir o interesse estratégico nacional ou segurança do Estado e da Sociedade, sendo-lhe atribuído um Termo de Classificação da Informação (TCI), estaremos diante de uma informação classificada, nos termos da Lei de Acesso à Informação. Se a restrição do acesso tem como objeto a proteção da intimidade, vida privada, a honra ou a imagem da pessoa natural identificada ou identificável, estaremos diante de uma informação pessoal, neste caso específico, chamamos a atenção para a falta de regulamentação para o tratamento de informações pessoais, pois, embora as informações classificadas tenham sido regulamentadas pelo Dec. 7.845/2012 este não contemplou as informações pessoais para as quais inexiste regulamento próprio em nosso ordenamento jurídico ${ }^{10}$. Podemos também nos deparar com dados ou informações que servem para subsidiar o processo decisório na Administração Pública, cujo sigilo seja necessário para garantir o efeito do ato administrativo, objeto da decisão, nesse caso estamos diante de documentos preparatórios que poderão ter seu acesso restrito até a publicação do ato. Nestes três casos, nos deparamos com dados ou informações cuja restrição do acesso encontra amparo na própria LAI.

A LAI, no entanto, recepciona todas as demais hipóteses legais de sigilo, ou seja, todos os direitos, valores ou objetos garantidos por meio da imposição de sigilo de acesso imposto por Lei ficam excepcionados do direito de acesso à informação garantido pela LAI.

O quadro 01 apresenta de forma mais sistematizada o objeto de trabalho da CPAI/Fiocruz, ou seja, as informações sigilosas.

Cabe destacar que o trabalho da CPAI/Fiocruz, portanto, não se restringiu a pensar apenas os casos de sigilo da Lei de Acesso à Informação, prevendo algumas das demais hipóteses de sigilo que poderiam ser pertinentes na instituição em questão, e criando instrumentos para orientar os profissionais no 
momento de identificar essas informações no universo de documentos com os quais se relacionam de forma cotidiana. Assim, ao orientar atentamente do que se trata esse restrito universo de informações que devem ser protegidas, garante-se maior segurança à instituição e certeza ao operador, entendido como o agente responsável pela criação ou envolvido em algum estágio do trâmite da informação dentro da instituição, para liberar as demais informações em transparência ativa, passiva, ou mesmo para a abertura dos dados governamentais, uma vez que esta tem como objetivo publicar e e compartilhar as base de dados de caráter público e não sigilosas. "O objetivo do Governo Aberto é transferir e compartilhar a base de dados de caráter público e não sigilosas, garantindo assim uma maior transparência do setor público, bem como fomentando a participação do cidadão"11.

Quadro 1- Panorama das informações sigilosas

\begin{tabular}{|c|c|c|c|c|}
\hline \multirow{4}{*}{ 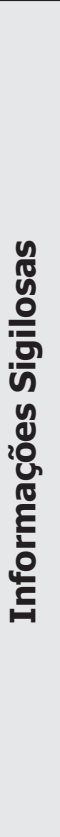 } & \multirow{3}{*}{$\begin{array}{l}\text { - Sigilo imposto } \\
\text { pela LAI }\end{array}$} & $\begin{array}{l}\text { Informações } \\
\text { Classificadas }\end{array}$ & $\begin{array}{l}\text { - Informações imprescindíveis } \\
\text { à segurança do Estado e da } \\
\text { Sociedade }\end{array}$ & $\begin{array}{l}\text { Informações passiveis de } \\
\text { classificação (RESERVA, SECRETA, } \\
\text { ULTRASSECRETA) }\end{array}$ \\
\hline & & $\begin{array}{l}\text { Informações } \\
\text { Pessoais }\end{array}$ & $\begin{array}{l}\text { - Informações relativas a } \\
\text { pessoa natural identificada ou } \\
\text { identificável }\end{array}$ & Sigilo de 100 anos \\
\hline & & $\begin{array}{l}\text { Informações contidas } \\
\text { em documentos } \\
\text { preparatórios }\end{array}$ & $\begin{array}{l}\text { - Informações que fundamentam } \\
\text { a tomada de decisão e o ato } \\
\text { administrativo }\end{array}$ & $\begin{array}{l}\text { Somente até a publicação da } \\
\text { decisão ou do ato administrativo }\end{array}$ \\
\hline & \multicolumn{2}{|c|}{ - Outras hipóteses legais de sigilo } & $\begin{array}{l}\text { - Sigilo Fiscal }{ }^{12} ; \\
\text { - Segredo de Indústria ou } \\
\text { comércio }^{13,14} ; \\
\text { - Segredo de Justiça, } \\
\text { - Sigilo Contábili } ; \\
\text { - Propriedade Intelectual }{ }^{16,17} ; \\
\text { - Sigilo Empresarial }{ }^{18} ; \\
\text { - Sigilo de Proposta de Preço }{ }^{19} ; \\
\text { - Sigilo de atos apuratórios }{ }^{20} ; \\
\text { - Sigilo contratual dentre outros. }\end{array}$ & $\begin{array}{l}\text { Estas modalidades de sigilo estão } \\
\text { previstas em leis específicas } \\
\text { com temporalidades de proteção } \\
\text { variadas. }\end{array}$ \\
\hline
\end{tabular}

Fonte: Produção do próprio autor.

Esse trabalho possibilitou também o enfretamento de questões relacionadas à Política Nacional de Dados Abertos, instituída pelo Decreto $n^{\circ}$ 8.777/2016, no sentido de permitir identificar o que de fato é objeto de abertura. Há uma diferenciação entre a universalidade dos dados governamentais, que são aqueles produzidos e acumulados pelo governo, e a especificidade dos dados públicos, que são dados governamentais sobre os quais não recaia imposição de sigilo ou restrição de acesso na forma da lei. Estes, submetidos a tratamento e disponibilizados no formato aberto, são denominados dados governamentais abertos. Portanto, todo dado governamental público pode, em tese, ser convertido em dado governamental aberto. O gráfico a seguir apresenta a disposição de cada um desses elementos dentro do universo dos dados governamentais.

Outro entendimento importante foi a não imposição do sigilo aos documentos, e sim a informações, o que permite que as informações e dados ostensivos em documentos controlados - aqueles que possuem informações sigilosas - possam, assim, ser disponibilizados aos cidadãos. A construção desse entendimento somente foi possível ao se dialogar com a prática e a legislação arquvística ${ }^{21}$, primeiramente porque estas informações, objeto do trabalho, são aquelas que expressam o produto do ato administrativo geradas no processo político-decisório e compõem os conjuntos arquivísticos do Estado, "Como tal, nas democracias contemporâneas os arquivos governamentais, seja como estoques ou serviços informacionais, são recursos 
fundamentais à governança e instrumentos de controle social sobre o Estado" ${ }^{22}$. Assim, a restrição é imposta à informação ou parte dela e não ao documento que a suporta.

Gráfico 01 - Representação dos dados governamentais na forma do Dec. 8.777/2016.

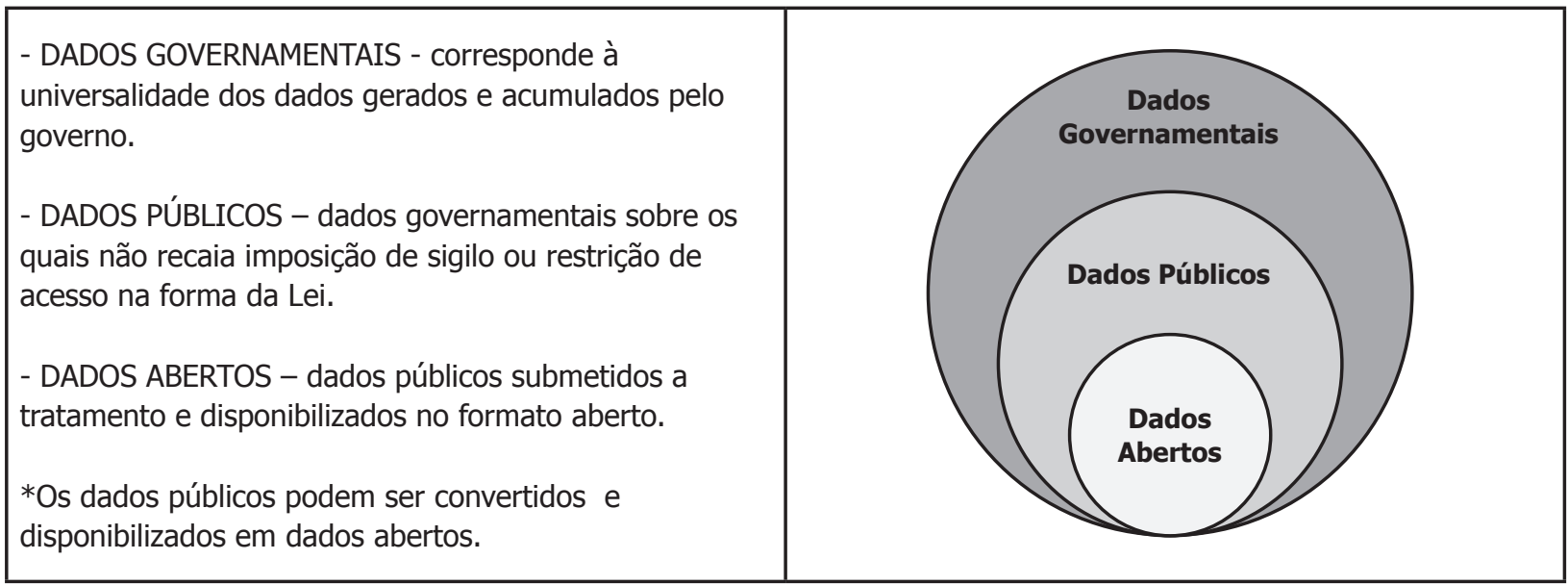

Fonte: produção do próprio autor.

Esse amadurecimento e trabalho culminou no documento "Procedimento para Tratamento e Classificação de Informações Sigilosas da Fiocruz”, etapa essencial para dar segurança necessária aos gestores e operadores de ações ligadas ao tratamento informacional e a promoção da transparência no ambiente institucional.

\section{Estabelecimento das etapas para promoção do controle de acesso às informações sigilosas}

Na criação do "Procedimento para Tratamento e Classificação de Informações Sigilosas da Fiocruz" o grupo trabalhou com o entendimento de que a imposição de restrições de acesso à informação exige da administração pública uma ação estritamente vinculada à norma, criteriosa, onde o administrador necessita ponderar entre o direito protegido, com a restrição do acesso à informação, e próprio direito à informação, para só então optar pelo critério menos lesivo ao interesse público. Assim, na tentativa de orientar de alguma maneira essa atividade, estabeleceu-se que o processo de imposição de restrição de acesso à informação seria realizado em quatro etapas: identificação, análise, sigilo e controle, como podemos verificar cada uma delas a seguir:

a. Identificação da informação sensível - diz respeito ao momento em que o operador na produção ou uso do documento se depara com a informação, ou no caso de uma demanda de acesso à informação, verifica a potencialidade lesiva a um direito, valor ou objeto caso a informação seja indiscriminadamente difundida;

b. Análise da sensibilidade da informação - identificada a potencialidade lesiva em caso de disseminação da informação, a verificação é aprofundada na etapa da análise, quando o operador pondera acerca dos efeitos decorrentes de uma eventual divulgação. Seria justificável a imposição do sigilo para proteção do direito em questão, tendo maior relevância do que o direito de acesso à informação?

c. Imposição do sigilo - feita essa ponderação, e permanecendo o entendimento de que é preciso restringir o acesso à informação, será necessário verificar se há disposição legal para se estabelecer a restrição do acesso à informação. Em caso positivo, se estabelece a restrição do acesso;

d. Adoção das medidas de controle - uma vez imposto o sigilo, será necessária a adoção de medidas para controle de acesso a essas informações, sendo preciso arcar com o ônus do trâmite mais rígido 
de documentação que contenha informação desta natureza, uma vez que se as informações são sigilosas a ponto de não poderem estar acessíveis ao cidadão, tampouco devem circular livremente dentro da instituição, devendo ser restritas àqueles profissionais que efetivamente tenham a comprovada necessidade de conhece-las.

Portanto, os documentos que contém informações sigilosas exigem um trâmite específico, com a definição de pessoas, ambientes e processos que possam subsidiar adequadamente a tarefa de controlar seu acesso $^{23}$. Além do estabelecimento de uma função, que pode contemplar profissionais de uma conjunção de áreas dentro da instituição, com a responsabilidade de tratar as informações sigilosas e operacionalizar o procedimento de classificação, desclassificação e reavaliação das informações sigilosas, é preciso ainda que uma série de outros cuidados sejam tomados ${ }^{24}$. Estes passam pela adequada marcação do documento, com indicação do grau de sigilo atribuído às informações, e pelo estabelecimento de procedimentos próprios para expedição (com protocolo e recibos próprios), tramitação, recebimento e arquivamento em ambiente e condições especiais que garantam minimamente os requisitos de segurança.

São necessárias ainda medidas para credenciar os profissionais que necessitem acessar esses documentos ${ }^{25}$, que devem se comprometer a manter o sigilo da informação, inclusive com assinatura de termo para esse fim. Da mesma maneira, são exigidos procedimentos específicos para possíveis reproduções destes documentos ${ }^{26}$.

Percebe-se, portanto, que lidar com informações contidas em documentos sigilosos não se trata de atividade trivial, a ser naturalizada na instituição para documentação que não aquela realmente relacionada a alguma hipótese de sigilo. Ou seja, ao orientar esse criterioso e devido tratamento às informações sigilosas, o que se pretende não é, de maneira alguma, promover qualquer cultura do sigilo; pelo contrário, a ideia é que esse custoso tratamento seja dado apenas às informações que assim o exigirem por serem efetivamente sigilosas, promovendo uma cultura de acesso às demais informações que não se enquadrarem nas restritas hipóteses de sigilo da LAI e de legislações específicas.

\section{Entendimentos sobre transparência, dados e informação}

A partir das experiências e conhecimentos mobilizados para desenvolvimento do trabalho descrito, outras questões e entendimentos sugiram na perspectiva de ações mais deliberadas voltadas à transparência da informação na instituição, tais como a criação de seu Plano de Dados Abertos e demais estratégias de aprimoramento da transparência passiva e ativa. Neste contexto, considera-se importante destacar a diferença entre a disseminação de informações em transparência ativa e a disponibilização de dados abertos. Tais diferenças recaem não somente em termos dos formatos sob os quais são disponibilizados, mas também considerando os possíveis usos/consumos destes, que podem abarcar um público mais ou menos amplo, que guardam especificidades relativas ao consumo/uso de dados abertos ou informações estruturadas, objeto da transparência.

Especificamente, trata-se de uma diferenciação dos produtos disponibilizados, seja pela sua natureza ou pelo seu uso (produtores / consumidores), pelas instituições públicas, seja por solicitação do cidadão, transparência ativa e passiva ou para cumprir as normas que estabelecem a abertura dos dados. Desta forma, verificou-se a necessidade do entendimento que apesar de estarem intrinsicamente conectados, dados e informação são objetos diferentes, gerando assim produtos, interesses e públicos diversos. Considerando o dado como um fato ou algo que não possui um significado imediato e, portanto, não proporciona compreensão para conclusões ou decisões, sem que sejam trabalhados.

A informação, neste contexto, é o trabalho e a estruturação dos dados, de forma a transmitir significado e compreensão dentro de um determinado contexto, neste sentido, a informação terá valor para produção de conhecimento quando percebida e acolhida com vistas a contribuir para o desenvolvimento tanto do 
indivíduo quanto do grupo que a percebe e acolhe, a influência dessa informação sobre quem a acolhe ou percebe, estará diretamente relacionada à influência que tem, sobre esse mesmo indivíduo ou grupo, quem a produziu ${ }^{27}$.

A abertura dos dados governamentais requer mecanismos e orientações específicas, sendo necessário respeitar padrões tecnológicos para que seu uso seja efetivo entre os sujeitos que tenham a competência para trabalhar com os mesmos ${ }^{28}$. Para cumprir com os requisitos da norma, os dados devem ser brutos e de formato aberto, possibilitando o reuso para diversos fins. Já a informação, objeto da LAI, não impõe padrões ou conhecimentos tecnológicos norteadores para seu uso. Trata-se de um objeto que precisa estar acessível de forma clara, transparente e em linguagem de fácil compreensão.

\section{Considerações finais}

Conforme relatado ao longo do presente artigo, a reflexão a respeito do restrito universo das informações sigilosas institucionais no âmbito da Fiocruz, com a criação de um grupo, de metodologias e de um instrumento específico para tratar a questão, permitiu não apenas a normatização da atividade de tratamento e classificação de informações sigilosas institucionais, mas também a criação de uma série de entendimentos que possibilitam que o trabalho disponibilização de dados e informações em acesso aberto possa se dar de maneira mais segura na instituição.

Nesta perspectiva, conclui-se que as normativas com a temática do acesso e abertura compreendem uma série de desdobramentos de iniciativas e procedimentos no cotidiano das instituições públicas, promovendo desafios que incluem as formas de planejamento e gestão dos dados, informações e documentos, buscando ao final ações mais transparentes para um governo aberto.

\section{Referências}

1. Brasil - Lei no 12.527, de 18 de novembro de 2011. Lei de Acesso à Informação - LAI.

2. Brasil - Decreto no 8.777, de 11 de maio de 2016. Institui a Política Nacional de Dados Abertos do Poder Executivo Federal.

3. Fundação Oswaldo Cruz (Brasil). Portaria da Presidência no 485/2014-PR, de 23 de maio de 2014. Institui a Comissão Permanente de Acesso a Informações da Fundação Oswaldo Cruz - CPAI.

4. Fundação Oswaldo Cruz (Brasil). Portaria da Presidência nº 484/2014-PR, de 23 de maio de 2014. Institui o Comitê Gestor da LAI.

5. Brasil. Decreto no 7.724, de 16 de maio de 2012. Regulamenta a LAI.

6. Heinen, J. Comentários à Lei de Acesso à Informação: Lei no 12.527/2011. Belo Horizonte: Fórum, 2014, p. 211.

7. Fernandez J, Morais GF. Segredo Industrial versus Lei de Acesso à Informação: uma contradição? Rio de Janeiro: Lumen Juris; 2014, p. 103-104.

8. Calderon MP. Lei de Acesso à Informação e seu impacto na atividade de inteligência. Campinas-SP: Mileniun Editora; 2014, p. 08.

9. Cunha Filho MC, Xavier VCS. Lei de Acesso à Informação: teoria e prática. Rio de Janeiro: Lumen Juris; 2014, p. 130.

10. Sales RG. Direito de Acesso à Informação Pública Administrativa. Rio de Janeiro: Lumen Juris; 2014, p.440.

11. Rodrigues IF. Dados governamentais abertos: meịo de promoção de transparência, controle e cocriação. In: CONGRESSO CONSAD DE GESTÃO PÚBLICA, 4, 2011, Brasília. Anais, p. 6.

12. Brasil. Constituição da República Federativa do Brasil (1988). Brasília-DF: Senado Federal, 1988, Art. 50, $X$ e Art. $14, \S 1^{\circ}$. 
13. Brasil. Lei no 9.279, de 14 de maio de 1996. Regula direitos e obrigações relativos à propriedade industrial, Art. 30; Art. 195, III, XI, XIV.

14. Brasil. Lei n 6.404, de 15 de dezembro de 1976. Dispõe sobre as Sociedades por Ações, Art. $155, \S 1^{\circ}$ e $\S 2^{\circ}$.

15. Brasil. Lei no 10.406, de 10 de janeiro de 2002. Institui o Código Civil, Art. 1.190 e Art. 1.191.

16. Brasil. Lei no 9.609, de 19 de fevereiro de 1998. Dispõe sobre a proteção da propriedade intelectual de programa de computador, Art. $3^{\circ}, \S 1^{\circ}$, III c/c $\S 2^{\circ}$ do mesmo artigo.

17. Brasil. Lei no 10.973, de 02 de dezembro de 2004. Dispõe sobre incentivos à inovação e à pesquisa científica e tecnológica no ambiente produtivo, Art. 12.

18. Brasil. Lei no 11.101, de 09 de fevereiro de 2005. Regula a recuperação judicial, a extrajudicial e a falência, Art. 169.

19. Brasil. Lei no 8.666, de 21 de junho de 1993. Lei de licitações e contratos da Administração Pública, Art. $3^{\circ}, \S 3^{\circ} \mathrm{c} / \mathrm{c}$ Art. 43, $\S 1^{\circ}$ e Art. 94.

20. Brasil. Lei no 8.112, de 11 de dezembro de 1990. Dispõe sobre o regime jurídico dos servidores públicos civis, Art. 150.

21. Brasil. Lei no 8.159, de 08 de janeiro de 1991. Lei de arquivos.

22. Jardim JM. A implantação da lei de acesso à informação pública e a gestão da informação arquivística governamental. Liinc em Revista, 2013; v. 9:.383-405.

23. Brasil. Decreto no 7.845, de 14 de novembro de 2012. Regulamenta procedimentos para credenciamento de segurança e tratamento de informação classificada.

24. Brasil. Ministério da Saúde. Portaria no 1.583, de 19 de julho de 2012. Dispõe, no âmbito do Ministério da Saúde e entidades a ele vinculadas, sobre a execução da LAI e regulamento.

25. Brasil. Gabinete de Segurança Institucional da Presidência da República. Norma Complementar $n^{0}$ 01 da Instrução Normativa no 02/DSIC/GSIPR de 27 de junho de 2013. Disciplina o credenciamento de segurança de pessoas naturais, órgãos e entidades públicas e privadas para o tratamento de informações classificadas.

26. Brasil. Gabinete de Segurança Institucional da Presidência da República. Norma Complementar n 20 da Instrução Normativa no 01/DSIC/GSIPR de 15 de dezembro de 2014. Diretrizes de segurança da informação e comunicações para instituição do processo de tratamento da informação nos órgãos e entidades da Administração Pública Federal.

27. Costa LF, Silva ACP, Ramalho FA. (Re)visitando os estudos de usuário: entre a "tradição" e o "alternativo". In DataGramaZero - Revista de Informação 2009; jul/ago v.10, n.4, p. 2

28. Open Government Partnership [homepage na internet]. 